\title{
Effects of radiation therapy on neuropsychological functioning in patients with nasopharyngeal carcinoma
}

\author{
P W H LEE, B K M HUNG,* E K W WOO, $\dagger$ P T H TAI, $\$$ D T K CHOI \\ From the Department of Psychiatry, Centre of Asian Studies, ${ }^{*}$ Department of Medicine, $\dagger$ University of Hong \\ Kong, and the Department of Radiotherapy, $\ddagger$ Queen Mary Hospital, Hong Kong
}

SUMMARY Sixteen patients who had a nasopharyngeal carcinoma (NPC) who were treated with radiation therapy were followed up after a median duration of 5.5 years and given a battery of neuropsychological tests. Results were compared with a comparable group of newly diagnosed NPC patients awaiting radiation therapy. The irradiated group was significantly poorer in overall IQ, nonverbal memory recall, and reported a substantially greater number of memory related complaints. These results contrast with the complacent general assumption that radiation therapy has a negligible effect on adult functioning.

The central nervous system is often exposed to considerable doses of irradiation. ${ }^{2}$ This happens when a primary or secondary tumour within the central nervous system is the target for radiation therapy and also when a tumour outside the central nervous system lies in its close proximity. Thus the temporal lobes are vulnerable to radiation therapy in patients with nasopharyngeal carcinoma (NPC) because they are in the path of the radiation beams.

Although there is now much evidence of the hazardous effects of radiation therapy on life expectancy, genetic structure ${ }^{3}$ and on the central nervous system ${ }^{4}$ there is little information about its effect on neuropsychological functioning. Consequently, patients' needs for information and after care of such effects after radiation therapy may have been underestimated. ${ }^{5}$ Neuropsychological studies on the effects of radiation therapy in adults are scant and poorly documented and in similar studies on children, the results are conflicting and inconsistent. Nevertheless two major trends are noted. First, most studies have indicated that the age at diagnosis and treatment is important and the age of 5 is generally regarded as a critical time. If CNS irradiation takes place before 5, the effect on the intellectual development of the child is likely to be serious. ${ }^{6-10}$ Secondly, the effect of radiation therapy, if present, mainly concentrates on the nonlanguage aspects of cognitive functioning. It is usually the

Address for reprint requests: Dr P W $\mathbf{H}$ Lee, Department of Psychiatry, Queen Mary Hospital, Hong Kong.

Received 22 April 1988.

Accepted 10 December 1988 performance scores of the intelligence test that are adversely affected.

Whether adverse neuropsychological effects occur in adults who have received radiation therapy is unclear. Radionecrosis of the temporal lobes developed after a mean interval of 60 months in a sma 4 group of seven subjects with nasophyaryngeal carcin oma studied retrospectively" but there are little dat on the neuropsychological functioning of such patients. The present study investigated the effect of radiation therapy on the neuropsychological functioning of adult patients with nasopharyngeal carcinoma. It was undertaken for two reasons. Firstly, while a number of studies have been done on children in this area, there are few data on adults. An unspoken but untested assumption seems to exist regarding the absence of adverse effects on adults. Secondly, by virtue of its location beneath the base of the skull and its propensity to spread through it, nasopharyngeal carcinoma does not lend itself to radical surgical excision, and radiation therapy remains the definitive treatment. ${ }^{12-14}$ Understanding how patients may be affected by this treatment is important for subsequent rehabilitation. This study employed both a prospective as well as cross-sectional design. The results of the cross-sectional study are now reported.

\section{Patients}

Between April and December 1987, patients with NPC followed up in the out-patient clinic of the Department of Radiotherapy, Queen Mary Hospital, were recruited into the study if they satisfied the following criteria: (1) age between 30 and $65,(2)$ staging at initial diagnosis being Stages I, II or 
$\mathrm{III}^{14}$, (3) received only a single course of radiation therapy without other modalities of treatment, such as chemotherapy, (4) at least 2 years after completion of the course of radiation therapy, (5) in complete remission with no evidence of disease clinically, endoscopically or radiologically; and (6) ambulatory without motor, sensory or cranial nerve deficits attributable to either disease or the effect of treatment.

During the same period, patients recently diagnosed with NPC and waiting for radiation therapy were included as controls (as well as prospective patients for the longitudinal segment of the study) if they satisfied the following criteria: (1) age between 35 and 65; and (2) staging at initial diagnosis being Stages I, II, or III.

Informed consent was obtained from all subjects. All subjects received a standard neurological examination and a cranial computed tomography (CT) to identify any area of radiation necrosis or any evidence of intracranial lesion.

Radiation therapy to the nasopharynx was delivered by a $8 \mathrm{MV}$ linear accelerator or a telecobalt- 60 unit. The whole treatment was divided into 2 phases. For phase 1, the nasopharynx was treated by two lateral opposing facial fields to half of the intended dose. For phase II, the nasopharynx was treated by a three-field technique consisting of two lateral opposing and one anterior facial field. The eyes, a large part of the tongue and brainstem were shielded from the lateral fields. The lateral part of the temporal lobes were also shielded together with the eyes in the anterior field. The dose schedule for the nasopharnyngeal regions consisted of 350 cGy mean tumour dose thrice per week to 59.5 Gy over 6 weeks (range 55-63 Gy), corresponding to a time and dose factor of 127 (range 118-135). Simultaneously, the neck was treated by an anterior cervical field to 52.5 Gy over $5 \frac{1}{2}$ weeks, with the larynx and the spinal cord shielded centrally. In all cases, as the superior margin of the treatment field was above the sella turcica and covered the sphenoid sinus, a potential site of tumour spread, part of both temporal lobes and the pituitary-hypothalamic axis would be within the target volume. The inferior parts of both temporal lobes were treated with a mean vertical span of $2.5 \mathrm{~cm}$ (range 2.2$2.8 \mathrm{~cm}$ ) to a mean estimated dose of $52.8 \mathrm{~Gy}$ (range 47 $57 \mathrm{~Gy})$.

\section{Methods}

All patients were assessed on a battery of neuropsychological tests by either one of the two psychologists involved in the study.

Tests of intellectual functioning. Patients' intellectual functioning was assessed using the information, comprehension, similarities, coding, and the block design subtests of the Wechsler Adult Intelligence Scale. The overall verbal, performance and full scale IQs were prorated and calculated on the basis of the subtests administered.

Tests of memory functioning. Memory functioning was assessed with three tests and a self-report memory checklist. The Logical Memory Test involved an immediate and a 30 minutes delayed recall of two short prose passages read to subjects. The score obtained was the number of segments of the stories correctly recalled. The Associate Learning Test required subjects to learn 10 pairs of word lists. A total of three presentations were given, and the score was calculated on the basis of the number of easy and difficult associations correctly learnt. The Rey Figure is a test of non-verbal memory recall where subjects were asked to copy a geometric figure (the Rey Figure) and then, without forewarning, to attempt to reproduce it after 30 minutes. The Subjective Memory Complaints checklist ${ }^{15}$ was administered to measure patients' own complaints relating to their memory functioning.

Other tests of global deficits: Three automated computer administered laboratory tests, and the Finger Tapping Test were included to measure more gross neuropsychological deficits. The Tachistoscope Test was used to measure visual information processing time. Slides consisting of a single digit number were presented through a Tachistoscope at a starting speed of $5 \mathrm{~ms}$. The minimal processing time was calculated on the basis of the time required for five consecutive correct identifications. The Motor Reaction Time Test required subjects to press or release a hand held button in response to the onset and cessation of a green or red light. Response speed and accuracy were measured. The Span of Apprehension Test was used to measure visual scanning and signal detection ability. An array of nine numbers was presented randomly placed in a $4 \times 4$ squares design with an exposure time of $75 \mathrm{~ms}$. Subjects were asked to identify whether a designated number was present in the array or not. This test also measured subjects' concentration and ability to adhere to a task despite the presence of background distractions. The Finger Tapping Test measured finger tapping speed of both the preferred and the nonpreferred hand using a standard finger tapping counter.

\section{Statistical methods}

Data were analysed with the aim of detecting differences in the performance of the patient and control subjects. All data collected were treated statistically using the Student t-test, and the 3-way analysis of variance test where appropriate, on a standard SPSS/PC + statistical package. ${ }^{16}$

\section{Results}

\section{Subject Characteristics}

Sixteen patients and 21 controls were studied. Their basic demographic data are shown in table 1 . Educational level of all subjects was concentrated towards the lower end, and the two groups were comparable. The median post-irradiation duration was 5.5 years (range $2 \cdot 5-10.2$ years). Two subjects in each group had co-existing medical diseases (see table 1). One patient was noted to have hypopituitarism and was on thyroxine replacement. Cranial CT was normal in the majority of subjects, with only two patients and one control showing CT features of a mild degree of cerebral atrophy. They were all aged 59 years or above. Intellectual Functioning: Scores on the intellectual tests administered were calculated on standard scaled score conversions as stipulated in the Manual of the WAIS. ${ }^{17}$ A comparison of results of the two groups indicated that the patient group obtained significantly lower scores than the control group in full scale IQ, verbal IQ, and performance IQ (see table 2). Specific areas of cognitive deficits noted were in recall of general 
Table 1 Background characteristics of patients and controls

\begin{tabular}{|c|c|c|c|}
\hline & Patient & Control & $p$ \\
\hline $\mathbf{N}$ & 16 & 21 & \\
\hline $\operatorname{Sex}(M: F)$ & $11: 5$ & $14: 7$ & n.s. \\
\hline $\begin{array}{l}\text { Age (Mean (s.d.)) } \\
\text { Number of co-morbid } \\
\text { diseases }\end{array}$ & $\begin{array}{c}48(9) \\
2+\end{array}$ & $\begin{array}{l}44(7) \\
2^{*}\end{array}$ & $\begin{array}{l}\text { n.s. } \\
\text { n.s. }\end{array}$ \\
\hline $\begin{array}{l}\text { Number with cerebral } \\
\text { atrophy on CT }\end{array}$ & 12 & 1 & n.s. \\
\hline $\begin{array}{l}\text { Educational level: } \\
\text { nil or primary } \\
\text { secondary } \\
\text { post-secondary } \\
\text { university }\end{array}$ & $\begin{array}{l}4 \\
8 \\
1 \\
3\end{array}$ & $\begin{array}{l}3 \\
7 \\
9 \\
2\end{array}$ & $\chi^{2}=6 \cdot 2, \mathrm{df}=3$, n.s. \\
\hline
\end{tabular}

*1 diabetes mellitus, 1 ischaemic heart disease.

$\dagger 2$ hypertension.

information from memory (Information), level of social understanding (Comprehension), and nonverbal concept formation involving the ability to analyse, synthesise, and reproduce abstract geometric designs (Block Design).

Memory Functioning: The patient group performed significantly poorer in the delayed recall of a geometric design, on the immediate recall of two verbally related short stories (Logical Memory test), and reported significantly more memory related problems as recorded from the Subjective Memory Complaints Checklist (see table 3). Delayed verbal memory recall of the same stories and associate learning of the two groups were not statistically different.

Other Neuropsychological Functions: Finger tapping speed of both the preferred and non-preferred hand in both groups were not significantly different. Speed of information processing and reaction time were not different. The patient group made significantly more errors in the Span of Apprehension Test compared $(\mathrm{t}=2 \cdot 39, \mathrm{p}=0.023)$ to the control group.

The Effects of Sex and Education on Neuropsychological Functioning: To further tease out the differential effects of radiation therapy, education and sex on the neuropsychological measures administered, a three way analysis of variance was calculated on variables that significantly differentiate between the experimental and control groups. Age, although a

Table 2 Comparison of patients and controls on intellectual functioning

\begin{tabular}{llll}
\hline & $\begin{array}{l}\text { Irradiated } \\
\text { NPC Patients }\end{array}$ & Controls & $\begin{array}{l}\text { t-value } \\
\text { (Significance) }\end{array}$ \\
\hline Information & 6.68 & 8.85 & $2.17 \mathrm{p}<0.05$ \\
Comprehension & 7.6 & 9.5 & $2.03 \mathrm{p}<0.05$ \\
Similarities & 6.25 & 8.85 & $1.40 \mathrm{n} . \mathrm{s}$. \\
Coding & 5.6 & 7.5 & $1.60 \mathrm{n} . \mathrm{s}$. \\
Block Design & 7.8 & 9.7 & $2.32 \mathrm{p}<0.05$ \\
Verbal IQ & 83.1 & 95.3 & $2.10 \mathrm{p}<0.05$ \\
Performance IQ & 89.1 & 99.0 & $2.04 \mathrm{p}<0.05$ \\
Full Scale IQ & 84.7 & 96.7 & $2.23 \mathrm{p}<0.05$ \\
\hline
\end{tabular}

Table 3 Comparison of patients and controls on memory functioning

\begin{tabular}{|c|c|c|c|}
\hline & $\begin{array}{l}\text { Irradiated } \\
\text { NPC Patients }\end{array}$ & Controls & $\begin{array}{l}\text { t-value } \\
\text { (Significance) }\end{array}$ \\
\hline $\begin{array}{l}\text { Rey Figure (Copy) } \\
\text { Rey Figure (Recall) } \\
\text { Logical Memory }\end{array}$ & $\begin{array}{l}87 \cdot 6 \\
38 \cdot 4\end{array}$ & $\begin{array}{l}96 \cdot 6 \\
57 \cdot 1\end{array}$ & $\begin{array}{l}1.83 \text { n.s. } \\
2.94 \mathrm{p}<0.01\end{array}$ \\
\hline $\begin{array}{l}\text { (Immediate Recall) } \\
\text { Logical Memory }\end{array}$ & $16 \cdot 8$ & $21 \cdot 5$ & $1.98 p<0.05$ \\
\hline $\begin{array}{l}\text { (Delayed Recall) } \\
\text { Associate Learning } \\
\text { Subjective Memory } \\
\text { Complaints }\end{array}$ & $\begin{array}{l}12 \cdot 9 \\
11 \cdot 3 \\
44 \cdot 8\end{array}$ & $\begin{array}{l}16 \cdot 9 \\
12 \cdot 3 \\
21 \cdot 0\end{array}$ & $\begin{array}{l}1 \cdot 15 \text { n.s. } \\
0.89 \text { n.s. } \\
2.24 \text { p }<0.05\end{array}$ \\
\hline
\end{tabular}

highly significant factor, was not included in the differential analyses because the mean age of two groups were not statistically different. Sex and educational level were noted significantly to affect patient scores in the information, comprehension, and block design subtests, and the verbal, performance and overall IQ. Immediate recall of verbal materials and delayed reproduction of the Rey Figures were also influenced by sex and education. Sex, education, and radiation therapy, however, did not exert an interactive additive or negative effect on one another (see table 4).

\section{Discussion}

While it must be stressed that all of our NPC patients were able to function at an acceptable level, there is little doubt that a significant number suffered from sub-clinical cognitive and intellectual deficits. Our present results indicated a general lowering of overall IQ, a poorer ability to retrieve information from long term memory (Information), a poorer ability to acquire and recall recently given non-verbal information (Rey Figures - delayed recall), and a poorer grasp of social realities (Comprehension) as major areas of problems after radiation therapy. The radiation therapy treated group tended also to respond to tasks in a rash and reflexive manner resulting in more errors and less well thought out solutions. In terms of anatomical correlations, the neuropsychological deficits were extensive and were not confined to functions mediated by the temporal lobes. This may be due to vascular changes affecting distant sites of lesion as radiation injury may not be confined to the limits of the radiation beams. The detrimental effects of radiation therapy were more conclusively demonstrated as the influence of sex and education was statistically separated out. Also, as patients in the control group may still be suffering from psychological distress relating to their recently discovered illness, they may be disadvantaged in their performance on neuropsychological tests as anxiety level is well documented to 
[able 4 3-way ANOVA on effects of radiation therapy, sex, and educational level on test performance

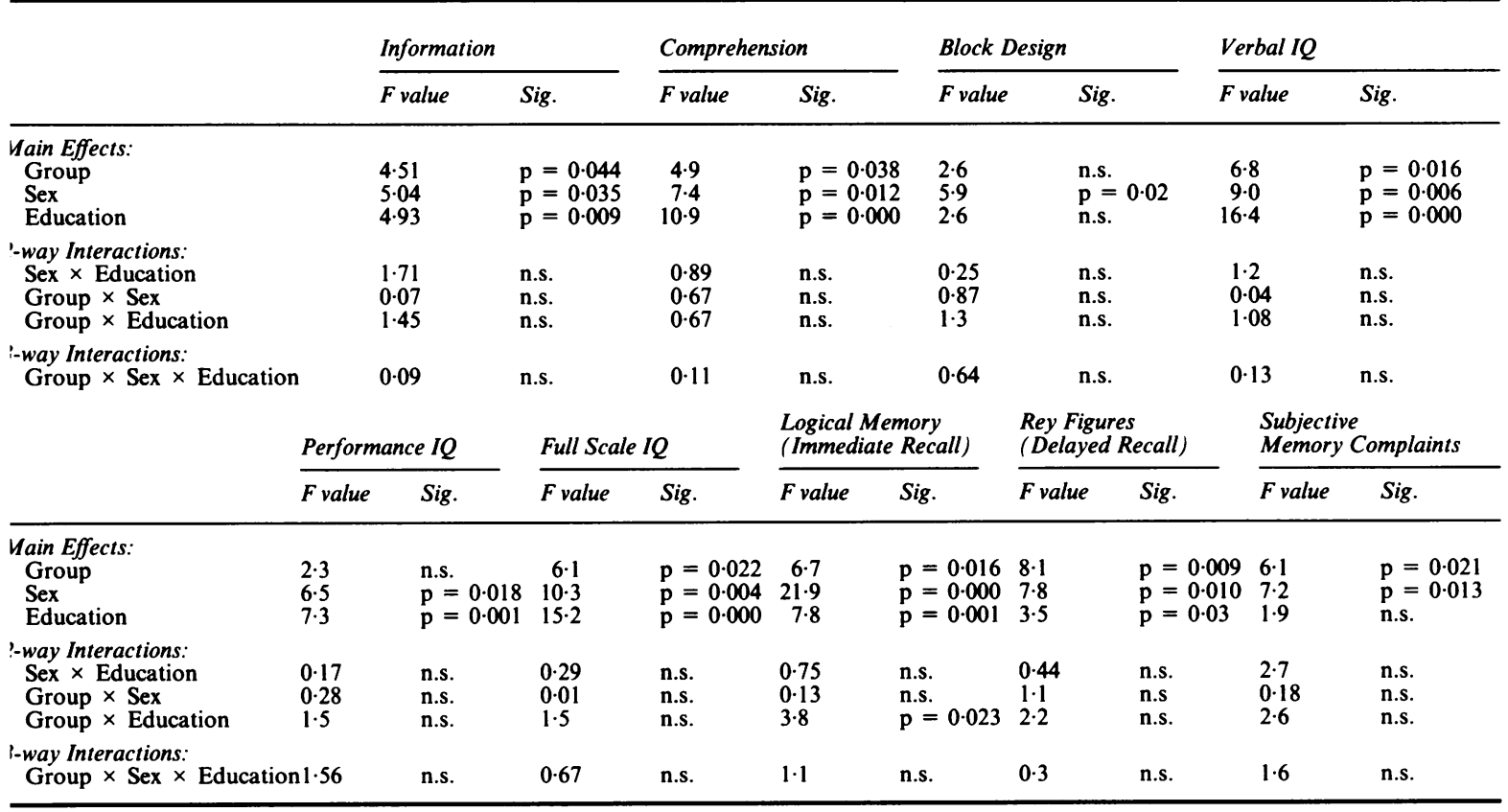

affect test results adversely. ${ }^{18}$ Despite this, the control subjects' better performance can be taken as a further documentation of the detrimental effects of radiation therapy on the cognitive functioning of NPC patients.

Sex and educational level were noted to have a significant effect on neuropsychological tests performance. Being females and having a low educational level tended to be associated with a lower score in memory and intellectual functioning assessment. The effects of sex, however, were dubious as an examination of our female subjects indicated that the majority of them had either no or very little formal education. From the analysis of variance results, curiously little interactive effects of sex, educational level and radiation therapy were detected. One exception was the immediate recall of verbal information where a better education was noted to enable subjects to achieve a higher percentage of recall despite detrimental radiation effects on other functions. This may be due to a better utilisation of memory and retrieval tactics provided by general education such that actual memory test performance was protected despite other detrimental influences.

As the majority of our patients had normal CT scans, little correlation was noted between neuropsychological functioning and radiological abnormalities. It must, however, be pointed out that CT may not detect subtle changes such as white matter abnormalities which may be better delineated with MRI.
Owing to the limitation of resources CT is the best guide we have at this stage.

Owing to the paucity of information on neuropsychological functioning on adult patients after radiation therapy, a brief review of findings from research on children is likely to provide some relevant pointers for our consideration. Positive results were generally noted in studies which compared the performance of leukaemic children with that of the normal population. Compared with healthy siblings, leukaemic children with radiation therapy were found to have significantly lower $I Q{ }^{8}{ }^{819}$ significantly poorer scores in verbal comprehension, perceptual organisation, freedom from distractibility and reading age assessment. ${ }^{7}$ Eiser and Lansdown ${ }^{6}$ also noted that radiation therapy effects were pronounced in producing poorer memory and motor skills particularly in younger children. Consistently positive results had been obtained, and the pattern of deficits was very closely similar to what we obtained in our present adult NPC population. It was not clear, however, from previous studies on children, as to whether the impairment was due to the state of ill health, the chemotherapy treatment or CNS irradiation, or a combination of the various factors. In our present study, however, the state of ill health clearly did not exert any deleterious effects as there was no indication that physical and neurological status were significantly poorer in the patient compared to the control group. 
In terms of recovery from effects of brain injury, two opposing views were evident in the literature. It had frequently been argued that injury to the central nervous system in children was less severe than comparable injury in the adult, and that the developing organism was endowed with compensatory mechanisms which the adult lacked. In line with this view, studies of brain injur $y^{20}$ reported that apparently similar degrees of injury had a less deleterious effect on children than on adults, and this applied especially to the recovery of language functions. An opposing view, however, stated that the less developed brain was more vulnerable to adverse influences than the mature brain. ${ }^{21}$ Thus, although extreme malnutrition did not appear to cause intellectual deterioration in the adult, the effects on children were severe and often irreversible. ${ }^{22}$ In our consideration of the effects of radiation therapy on the adult NPC patient population, recovery from the subtle intellectual and cognitive deficits may be more complex. The detrimental effects of such deficits may extend not just to problem solving ability, but also to social and occupational functioning. The potential negative downward spiralling effects of deficient neuropsychological functioning on the patient's ability to function in other areas of life may require serious attention. We pointed out in a previous report" that the paucity of "mild" cases in the literature on cerebral radionecrosis may be more apparent than real as a result of underreporting. Perhaps another reason was that deficits were often not detected due to the limited opportunity that patients had in gaining access to a proper neuropsychological examination of cognitive functions.

With a more informed understanding of the likely hazardous effects of radiation therapy, better preventive as well as rehabilitative measures can be taken. Preventive measures would include proper shielding, and due consideration of the optimal total dose of radiation and its fractionation. Rehabilitative measures would include early secondary prevention and early skills retraining ${ }^{23}$ as and when indicated on the basis of a more comprehensive documentation of cognitive deterioration which may often be detectable at an earlier and more manageable stage.

A follow-up study of the control subjects after they complete their radiation therapy is planned. Repeat assessment and comparison of the data with baseline measures will more definitively point to areas of deficits arising from radiation therapy. The likely effects on cognitive, social and occupational functioning, as well as any structural changes associated with radiation therapy will be measured over time. The effects and progression of probable neuropsychological as well as social and occupational deterioration will be reported in due course.
The authors thank Mr Ben Cheung for his assistance in data processing and statistical analyses.

\section{References}

1 Glass JP, Hwang T-L, Leavens ME, Libshitz HI. Cerebral radiation necrosis following treatment of extracranial malignancies. Cancer 1984;54:1966-72.

2 Di Lorenzo N, Nolletti A, Palma L. Late cerebral radioneceosis. Surg Neurol 1978;10:281-90.

3 Roberts T, Bleecham NM. Health hazards of radiotherapy. Public Health Review 1980;9:37-66.

4 Duffner PK, Cohen ME, Thomas PRM, Lansky SB. The longterm effects of cranial irradiation on the central nervous system. Cancer 1985;56:1841-6.

5 Eardley A. Radiotherapy: what are patients' needs? European J Surg Oncology 1985;11:353-5.

6 Eiser C, Lansdown R. Retrospective study of intellectual development in children treated for acute lymphoblastic leukaemia. Arch Dis Childhood 1977;52:525-9.

7 Eiser C. Intellectual abilities among survivors of childhood leukaemia as a function of CNS irradiation. Arch Dis Childhood 1978;53:391-5.

8 Moss AH, Nannis ED, Poplack DG. The effects of prophylactic treatment of the central nervous system on the intellectual functioning of children with acute lymphocytic leukaemia. Am J Med 1981;71:47-52.

9 Meadows AT, Gordon J, Massari DJ, Littman P, Fergusson J, Moss K. Declines in IQ scores and cognitive dysfunctions in children with acute lymphocytic leukaemia treated with cranial irradiation. Lancet $1981 ; \mathrm{i}: 1015-8$.

10 Copeland DR, Fletcher JM, Pfefferbaum-Levine B, Jaffe N, Ried H, Maor M. Neuropsychological sequelae of childhood cancer in long-term survivors. Pediatrics 1985;75:745-53.

11 Woo E, Lam K, Yu YL, Lee PWH, Huang CY. Cerebrał radionecrosis: is surgery necessary? J Neuro Neurosur Psyo chiatry 1987;50:1407-14.

12 Ho JHC. Nasopharyngeal carcinoma. Western J Med 198 143:70-3.

13 Ho JHC, Lau WH, Fong M, Chan CL, Au GKH. Treatment of nasopharyngeal carcinoma (NPC). In: Grundmann E, ed. Cancer Campaign, vol. 5, Nasopharyngeal carcinoma. Chicago, 1981;279-85.

14 Ho JHC. Stage classification of nasopharyngeal carcinoma: a review. In: de The G, Ito Y, eds. Nasopharyngeal carcinoma: etiology and control. Lyon: IARC Scient Pub, 1978;20:113.

15 Fung ASM. A study of the memory functioning in the infarct patients: the relationships between test performance, subjective complaints, and behavioural indexes. Unpublished manuscript, 1987.

16 Nourusis MJ. Advanced Statistics: SPSS/PC + . SPSS Inc 1986.

17 Wechsler D. WAIS Manual. The Psychological Corporation 1955.

18 Allison J, Blatt SJ, Zimet CN. The interpretation of psychological tests. New York: Harper \& Row, Pub; 1968.

19 Jannoun L. Are cognitive and educational development affected by age at which prophylactic therapy is given in acute lymphoblastic leukaemia? Arch Dis Childhood 1983;58:953-8.

20 Lenneberg EH. Biological Foundations of Language. New York: Wiley, 1967.

21 Dobbing J. Vulnerable periods in developing brains. In: Davison AN, Dobbing J, eds. Applied Neurochemistry. Oxford: Blackwell, 1968.

22 Hoorweg J, Stanfield JP. The effects of protein energy malnutrition in early childhood on intellectual and motor abilities in late childhood and adolescence. Dev Med Child Neuro 1976;18: 330-50.

23 Meier MJ, Benton AL, Diller L. Neuropsychological rehabilitation. New York: Churchill Livingstone, 1987. 